\title{
Influence of annealing temperature on the sensitivity of nickel oxide nanosheet films in humidity sensing applications
}

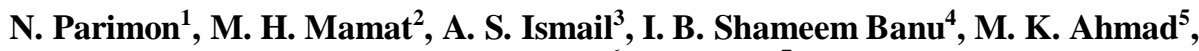 \\ A. B. Suriani', M. Rusop ${ }^{7}$ \\ ${ }^{1,2,3,7}$ NANO-ElecTronic Centre (NET), Faculty of Electrical Engineering, Universiti Teknologi MARA (UiTM), Malaysia \\ ${ }^{2,7}$ NANO-SciTech Centre (NST), Institute of Science (IOS), Universiti Teknologi MARA (UiTM), Malaysia \\ ${ }^{1,3}$ Faculty of Engineering, Universiti Malaysia Sabah (UMS), Malaysia \\ ${ }^{4}$ Department of Physics, B.S. Abdur Rahman Crescent Institute of Science \& Technology, India \\ ${ }^{5}$ Microelectronic and Nanotechnology-Shamsuddin Research Centre (MiNT-SRC), \\ Faculty of Electrical and Electronic Engineering, Universiti Tun Hussein Onn Malaysia (UTHM), Malaysia \\ ${ }^{6}$ Nanotechnology Research Centre, Faculty of Science and Mathematics, \\ Universiti Pendidikan Sultan Idris (UPSI), Malaysia
}

\begin{tabular}{l}
\hline \hline Article Info \\
\hline Article history: \\
Received Aug 18, 2019 \\
Revised Oct 20, 2019 \\
Accepted Nov 3, 2019
\end{tabular}

Keywords:

Annealing temperature

Humidity sensing

Nickel oxide

Sensitivity

Sol-gel immersion

\begin{abstract}
Nickel oxide ( $\mathrm{NiO}$ ) nanosheet films were successfully grown onto $\mathrm{NiO}$ seedcoated glass substrates at different annealing temperatures for humidity sensing applications. $\mathrm{NiO}$ seed layers and $\mathrm{NiO}$ nanosheet films were prepared using a sol-gel spin coating and sonicated sol-gel immersion techniques, respectively. The properties of $\mathrm{NiO}$ nanosheet films at asdeposited, $300{ }^{\circ} \mathrm{C}$, and $500{ }^{\circ} \mathrm{C}$-annealed were examined by X-ray diffraction (XRD), field emission scanning electron microscopy (FESEM), ultravioletvisible (UV-vis) spectroscopy, and humidity sensor measurement system. The XRD patterns demonstrate that the grown $\mathrm{NiO}$ films have crystalline cubic structures at temperature of $300{ }^{\circ} \mathrm{C}$ and $500{ }^{\circ} \mathrm{C}$. The FESEM images show that the large porous nanosheet network spread over the layers as the annealing temperature increased. The UV-vis spectra revealed that all the nanosheet films have the average transmittance below than $50 \%$ in the visible region, with absorption edges $\sim 350 \mathrm{~nm}$. The optical band gap energy was evaluated in ranges of 3.39 to $3.61 \mathrm{eV}$. From the obtained humidity sensing results, it shows that $500{ }^{\circ} \mathrm{C}$-annealed film exhibited the best sensitivity of 257 , as well as the slowest response time, and the fastest recovery time compared with others.
\end{abstract}

Copyright $(0) 2020$ Institute of Advanced Engineering and Science. All rights reserved.

\section{Corresponding Author:}

M.H. Mamat,

NANO-ElecTronic Centre (NET),

Faculty of Electrical Engineering,

Universiti Teknologi MARA (UiTM),

40450 Shah Alam, Selangor, Malaysia.

Email: mhmamat@uitm.edu.my

\section{INTRODUCTION}

Due to the high demand for highly selective, stable, and sensitive humidity sensors, research is still ongoing to find novel materials with optimization to achieve this goal. The latest investigation shows that metal oxides have achieved the best consideration in sensing applications [1] including humidity sensor since it can be synthesized with high surface area [2] and large pore volume [3]. Besides, the performance of the metal oxide-based sensor also depends on the thickness of the film and its operating temperature $[4,5]$. There are other advantages of using metal oxides as a sensing material such as low-cost preparation [3], high sensitivity, fast response and recovery time [4], and also controllable synthesis [6]. Generally, there are 
two kinds of metal oxide-based sensors that are always in use. They are n-type metal-oxides whose majority carrier is an electron and p-type metal-oxides whose majority carrier is a hole [4]. Although most n-type metal oxides were used in sensing applications, the p-type is also among the preferred option, especially nickel oxide $(\mathrm{NiO})$.

Previously, few reports based on $\mathrm{NiO}$ and its nanocomposites such as $\mathrm{NiO} / \mathrm{Al}_{2} \mathrm{O}_{3}$ [7], $\mathrm{CuO}-\mathrm{NiO}$ [8], $\mathrm{NiO}-\mathrm{SnO}_{2}$ [9], and $\mathrm{MoO}_{3}-\mathrm{NiO}$ [10] have been utilized as the materials for humidity sensor applications. Nevertheless, the humidity sensors using a single compound of $\mathrm{NiO}$ without composite structure could also be fabricated. $\mathrm{NiO}$ is one of the metal oxides, which have been generally reported to have a wide bandgap ( 3.6 to $4.0 \mathrm{eV}$ ) between the valence and conduction bands. $\mathrm{NiO}$ exhibits the p-type conductivity and can be characterized by its high thermal stability and good chemical stability [3,11, 12]. It shows the characteristics of high surface to volume ratio, and good optical transparency and electrical conductivity [3, 13]. Besides, the unique structure of nanostructured $\mathrm{NiO}$ substances could facilitate interesting characteristics and performance of the fabricated sensor.

Previous researches have been conducted to increase the surface properties of $\mathrm{NiO}$ through variation of deposition technique [12,14], type of precursor [15], and different annealing temperature [16, 17] since the improved surface properties could enhance the humidity response. The annealing temperature has typically impacted the crystal growth as well as the surface area of the nanostructures, which influences the response and sensitivity of $\mathrm{NiO}$ substance during the humidity sensing activity. Therefore, the study on the fabrication of $\mathrm{NiO}$ at varying annealing temperatures could provide an interesting task towards improvement and optimization of humidity sensing particularly at temperature of $500{ }^{\circ} \mathrm{C}$ and below. This is due to the fact that most $\mathrm{NiO}$ materials are studied at high annealing temperature.

Amongst the common deposition techniques of NiO nanostructures, the sol-gel method [18, 19] has received wide attention for the preparation of $\mathrm{NiO}$ at specific textural and microstructural characteristics [7]. Therefore, the deposition processes based on sol-gel including spin coating and immersion method have been used in this study. These techniques seem to be rather promising and have been considered as facile and fast fabrication processes compared to other methods. In the previous reports, research has been conducted to fabricate $\mathrm{NiO}$ on the substrate; however, the $\mathrm{NiO}$ film was grown on the ITO-coated glass substrate [3, 20]. Accordingly, this two-dimensional (2D) NiO nanosheet films were prepared on seed-coated glass substrates at different annealing temperatures and their humidity sensing properties were studied in term of their sensitivity.

\section{RESEARCH METHOD}

Before the growth of $\mathrm{NiO}$ nanosheets was carried out, the seed layers deposition process on the glass substrate was conducted. It started with the cutting process of glass substrates into $2.5 \mathrm{~cm} \times 2.5 \mathrm{~cm}$ each. Then, the substrates were cleaned in a hydrochloric acid solution. Next, the substrates were cleaned using solutions of acetone, ethanol, and de-ionized (DI) water in the ultrasonic bath (Hwasin Technology PowerSonic 405, 40k Hz) for 15 minutes each. Finally, the glass substrates were blown using nitrogen gas for drying. $\mathrm{NiO}$ seed layers were prepared using the sol-gel spin-coating method in which $0.2 \mathrm{M}$ nickel acetate $\left(\mathrm{Ni}\left(\mathrm{CH}_{3} \mathrm{COO}\right)_{2} .4 \mathrm{H}_{2} \mathrm{O}\right)$ (Friendemann Schmidt), diethanolamine $\left(\mathrm{C}_{4} \mathrm{H}_{11} \mathrm{NO}_{2}\right)$, and ethylene glycol monoethyl ether $\left(\mathrm{C}_{4} \mathrm{H}_{10} \mathrm{O}_{2}\right)$ were used as the precursor, stabilizer, and solvent, respectively. The solution was prepared using $50 \mathrm{ml}$ solvent and $2 \mathrm{ml}$ DEA. The solution was stirred for 2 hours at room temperature. The seed layers were deposited on top of the glass substrates using the spin coater at the deposition speed of $4000 \mathrm{rpm}$. The coating process was repeated for five times. The seed-coated films were dried at $250{ }^{\circ} \mathrm{C}$ for 5 minutes for each layer before annealed at $400{ }^{\circ} \mathrm{C}$ for 2 hours.

For the deposition of $\mathrm{NiO}$ nanosheet, sonicated sol-gel immersion technique was applied. The $\mathrm{NiO}$ nanosheets were grown onto $\mathrm{NiO}$ seed-coated glass substrates at different annealing temperatures to look into their performance towards humidity sensing. To grow $\mathrm{NiO}$ nanosheet films, a solution consisting of $0.2 \mathrm{M}$ nickel (II) nitrate hexahydrate $\left(\mathrm{Ni}\left(\mathrm{NO}_{3}\right)_{2} \cdot 6 \mathrm{H}_{2} \mathrm{O}\right)$ (Friendemann Schmidt) as a precursor and $0.2 \mathrm{M}$ hexamethylenetetramine $\left(\mathrm{C}_{6} \mathrm{H}_{12} \mathrm{~N}_{4}\right)$ (Sigma-Aldrich) as a stabilizer was prepared in a beaker filled with DI water. The solution was sonicated using the ultrasonic bath for 30 minutes. Next, the solution was stirred for 45 minutes at a constant speed of $300 \mathrm{rpm}$ in ambient. The solution then was poured into the Schott bottles, where the $\mathrm{NiO}$ seed-coated glass substrates were located at the bottom. Afterwards, the bottles were immersed in a water bath instrument for 2 hours at a temperature of $95{ }^{\circ} \mathrm{C}$. After the immersion process, the deposited $\mathrm{NiO}$ nanosheet film samples were taken out from the bottles and rinsed with DI water. The films were further blown with nitrogen gas for drying. Then, the samples were pre-baked for 15 minutes in a furnace at $150{ }^{\circ} \mathrm{C}$ followed by the annealing process at different temperatures of $300{ }^{\circ} \mathrm{C}$ and $500{ }^{\circ} \mathrm{C}$ within 1 hour for each sample. The as-deposited sample (non-annealed) was also prepared for reference. 
The NiO nanosheet films then were characterized using field emission scanning electron microscopy (FESEM, JEOL JSM-7600F) for the surface morphological studies. The crystallinity was investigated using X-ray diffraction (XRD, PANalytical X'Pert PRO). The optical transmittances of the grown NiO nanosheet films were characterized using ultraviolet-visible (UV-vis) spectrophotometer (Jasco/V-670 EX). The humidity sensor measurements of the devices were performed using a sensor measurement system (Keithley 2400) and humidity chamber (ESPEC-SH261). For humidity sensor measurement, platinum (Pt) contacts were deposited on top of the nanosheet films by using thermal evaporation system (Ulvac VPC 1100 ) with the thickness of the metal contact was fixed at $60 \mathrm{~nm}$.

\section{RESULTS AND ANALYSIS}

\subsection{X-Ray Diffraction Patterns of $\mathrm{NiO}-\mathrm{Ni}(\mathrm{OH})_{2}$ Nanosheet Films}

The XRD patterns of $\mathrm{NiO}$ nanosheet films at different annealing temperatures in the $2 \theta$ ranges of $20^{\circ}$ to $80^{\circ}$ are shown in Figure 1(a). The measurement was conducted to confirm that each sample consisted of crystalline $\mathrm{NiO}$ during the immersion and annealing processes. The XRD patterns indicate that $300{ }^{\circ} \mathrm{C}$ and $500{ }^{\circ} \mathrm{C}$-annealed samples display polycrystalline structures, which can be indexed to the cubic type of $\beta$-NiO (JCPDS NO.47-1049). From the diffraction patterns, it can be clearly observed that the intensity of the XRD peaks increase when the films were annealed at high temperature. Four diffraction peaks were recorded in the XRD spectrum of the $\mathrm{NiO}$ nanosheet film annealed at $500^{\circ} \mathrm{C}$. These peaks were indexed to the (111), (200), (220), and (222) crystal planes of approximately at $36.7^{\circ}, 42.7^{\circ}, 62.3^{\circ}$ and $78.7^{\circ}$, respectively. The peaks of $500{ }^{\circ} \mathrm{C}$-annealed $\mathrm{NiO}$ can be seen narrower than $300^{\circ} \mathrm{C}$-annealed sample, which indicates that this nanosheet film has the best crystalline quality. The $300{ }^{\circ} \mathrm{C}$-annealed $\mathrm{NiO}$ shows broader diffraction peaks than $500{ }^{\circ} \mathrm{C}$ annealed NiO. These peaks were indexed to three diffraction peaks which are (111), (200), and (220) orientations at $36.7^{\circ}, 43.0^{\circ}$ and $62.1^{\circ}$, respectively.

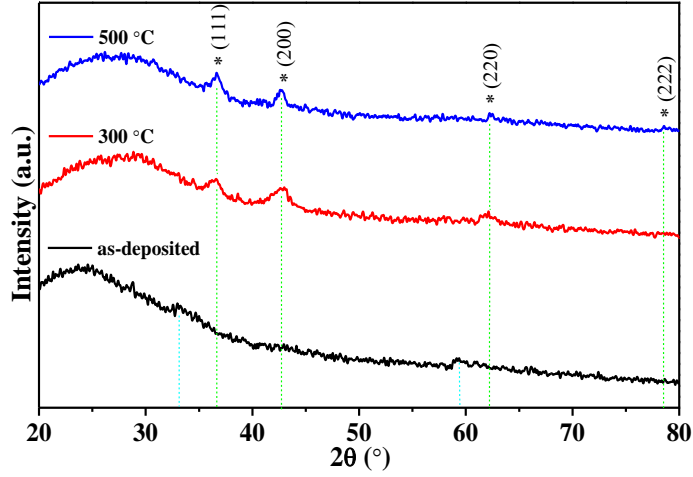

(a)

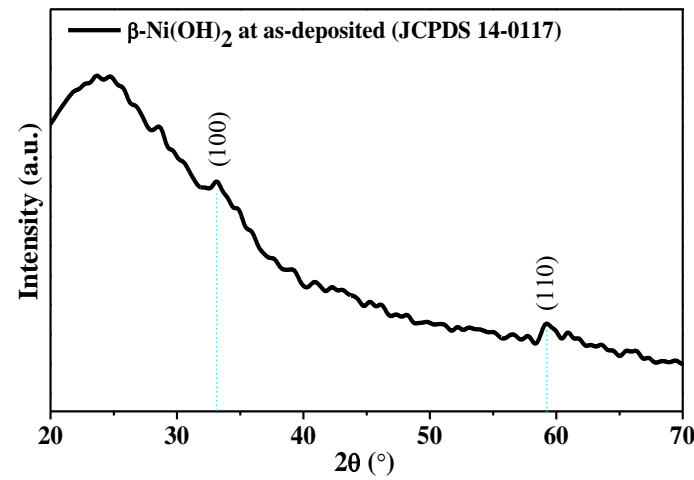

(b)

Figure 1. (a) XRD patterns of the as-deposited, $300^{\circ} \mathrm{C}$-annealed and $500{ }^{\circ} \mathrm{C}$-annealed NiO. (b) The diffraction pattern of as-deposited $\mathrm{Ni}(\mathrm{OH})_{2}$

Meanwhile, the diffraction peaks for the as-deposited sample displays weaker intensity as compared with $300{ }^{\circ} \mathrm{C}$ and $500{ }^{\circ} \mathrm{C}$-annealed samples, where we can see the peak of $\mathrm{NiO}$ has not yet existed. This situation revealed that the crystallinity of as-deposited nanosheet film is poor and the formation of $\mathrm{NiO}$ structure is still incomplete. However, there are two small diffraction peaks of $\mathrm{Ni}(\mathrm{OH})_{2}$ for the as-deposited film as shown in Figure 1(b). These peaks were indexed to the (100), and (110) planes of hexagonal $\beta-\mathrm{Ni}(\mathrm{OH})_{2}$ (JCPDS 14-0117) correspond to 33.1 ${ }^{\circ}$, and 59.3 ${ }^{\circ}$, respectively. As mentioned by Zhao et al. [21], $\beta-\mathrm{Ni}(\mathrm{OH})_{2}$ was recognized as isostructural with brucite and consists of closely stacked $2 \mathrm{D} \mathrm{Ni}(\mathrm{OH})_{2}$. In conclusion, no peaks associated with $\beta-\mathrm{Ni}(\mathrm{OH})_{2}$ were observed for $300{ }^{\circ} \mathrm{C}$ and $500{ }^{\circ} \mathrm{C}$-annealed samples showing that $\beta-\mathrm{Ni}(\mathrm{OH})_{2}$ was completely converted to $\mathrm{NiO}$ in these temperatures. Moreover, the diffraction peaks of $\mathrm{NiO}$ crystals become stronger and narrower with increasing annealing temperature, indicating that the degree of $\mathrm{NiO}$ crystallinity [21].

\subsection{Surface Morphological Characterization}

The surface morphology images of $\mathrm{NiO}$ nanosheet films at different annealing temperatures were characterized using FESEM. The images as shown in Figure 2 were arranged according to the sequence of 
their annealing temperature which is (a) as-deposited, (b) $300{ }^{\circ} \mathrm{C}$, and (c) $500{ }^{\circ} \mathrm{C}$ at a magnification of $50,000 \times$. The growth of $\mathrm{NiO}$ nanosheet films is heavily influenced by the $\mathrm{NiO}$ seed layer acting as a seeded catalyst. It can be observed that the $2 \mathrm{D} \mathrm{NiO}$ nanosheet films uniformly grew and exhibited almost the same morphology on the $\mathrm{NiO}$ seed-coated glass substrates for all samples. It is also noted that a large porous network assembled by plenty of two-dimensional plain curving $\mathrm{NiO}$ [3] spreads over the coating layers. In addition, the porous channel structure was grown even for the non-annealed film although the image of the petals is not so sharp and clear as can be observed in Figure 2(a).

However, when the annealing temperature was applied at $500{ }^{\circ} \mathrm{C}$, the nanosheet exhibits a hollow structure with the presence of tiny black spots on the nanosheet surface as reported by Mamat et al. [20]. They mentioned that the black spot with high density represents small void and originated from the evaporation of $\mathrm{OH}$ group and impurities at a high temperature. In addition, the structure of $500{ }^{\circ} \mathrm{C}$-annealed becomes split and conglomerating, which indicates that a serious aggregation phenomenon occurs during the higher annealing temperature, resulting in a slightly changed in the surface area [21]. Therefore, the surface area of the nanosheets is expected to provide more adsorption of water molecules when exposed to humidity sensing activity. According to clarification from Kennedy et al. [13], the enhancement of sensing properties strongly depends on the surface properties which works on the principle of chemical and physical adsorption of water on the surface. For this reason, different annealing temperature plays an important role in determining the morphology and structural properties of $\mathrm{NiO}$ nanosheet films thus determining different performance against humidity sensors. Further, an explanation of chemical reactions for the formation of $\mathrm{NiO}$ nanosheet films can be followed in our previous work [3].
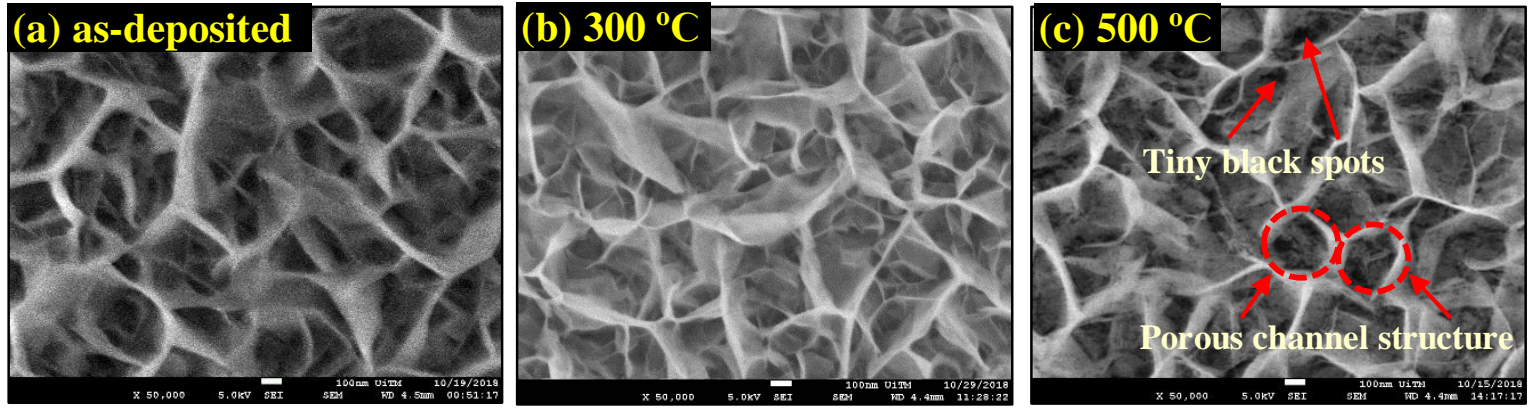

Figure 2. The surface morphologies of (a) as-deposited, (b) $300{ }^{\circ} \mathrm{C}$, and (c) $500{ }^{\circ} \mathrm{C}$-annealed NiO nanosheet films at a 50,0000× magnification

\subsection{Optical Transmittance, Absorption Coefficient, and Energy Band Gap}

The transmittance measurement of $\mathrm{NiO}$ nanosheet films as a function of annealing temperature were carried out in the wavelength ranges between $300 \mathrm{~nm}$ to $800 \mathrm{~nm}$ as shown in Figure 3(a). The transmittances in the visible region $(400-800 \mathrm{~nm})$ were estimated to be approximately $38 \%, 14 \%$, and $45 \%$ for asdeposited, $300{ }^{\circ} \mathrm{C}$, and $500{ }^{\circ} \mathrm{C}$-annealed $\mathrm{NiO}$ nanosheet films, respectively. These results show that all the transmittance percentages are less than $50 \%$. The lowest transmittance percentage was identified at $300{ }^{\circ} \mathrm{C}$ annealed film. It can be suggested that the transmittance percentages and the properties of $\mathrm{NiO}$ nanosheet films are changing according to the annealing temperature. This condition may be due to the variation of $\mathrm{NiO}$ nanosheet film thickness when annealed at different temperatures. Generally, low transmittance percentage is due to the high thickness of the nanosheet film as mentioned by Malliga et al. [22]. In addition, the variation of film colours also resulting in the variation of transmittance percentages. For $300{ }^{\circ} \mathrm{C}$-annealed sample, the film colour is blackish and slightly darker compared to the other nanosheet films causing the transmittance percentage to be the lowest.

The absorption coefficients spectra of $\mathrm{NiO}$ nanosheet films produced at various annealing temperatures are presented in Figure 3(b). The spectra reveal that the $300{ }^{\circ} \mathrm{C}$-annealed $\mathrm{NiO}$ exhibits the highest UV absorption properties at wavelength below than $340 \mathrm{~nm}$, while as-deposited showing the lowest.

To determine the optical bandgap $\left(E_{\mathrm{g}}\right)$ of $\mathrm{NiO}$ nanosheet films, the Tauc's plot was constructed and presented in Figure 4 . The $E_{\mathrm{g}}$ were determined from the extrapolated linear line of the graph of $(\alpha h v)^{2}$ versus photon energy with estimated value are $3.39,3.62$, and $3.53 \mathrm{eV}$ for as-deposited, $300{ }^{\circ} \mathrm{C}$, and $500{ }^{\circ} \mathrm{C}$ annealed, respectively. It shows that the annealing temperature affects strongly on the bandgap energies as mentioned by Yazdani et al. [23]. From the results, the as-deposited and $500{ }^{\circ} \mathrm{C}$-annealed samples are slightly missed from the estimated value that reported which is within 3.6 to $4.0 \mathrm{eV}$. However, some reported that the 
$\mathrm{NiO}$ band gap was between 3.2 and 3.8 [21]. For the case of $500{ }^{\circ} \mathrm{C}$-annealed sample, this result may be caused by the increase of lattice disorder and defect states upon the application of high annealing temperature. For the as-deposited sample, the lowest $E_{g}$ value may be due to the thickness of the film, which is about $882 \mathrm{~nm}$ and smaller compared to other samples. The thicknesses of other samples are approximately $751 \mathrm{~nm}$ and $787 \mathrm{~nm}$ for $300{ }^{\circ} \mathrm{C}$ and $500{ }^{\circ} \mathrm{C}$-annealed, respectively. The width of the $E_{\mathrm{g}}$ of the films can be determined from the following (1) [20, 24]:

$$
(\alpha h v)^{2}=A\left(h v-E_{g}\right)
$$

where $E_{\mathrm{g}}, \alpha, A$, and $h v$ is the optical bandgap, absorption coefficient, constant, and photon energy, respectively.

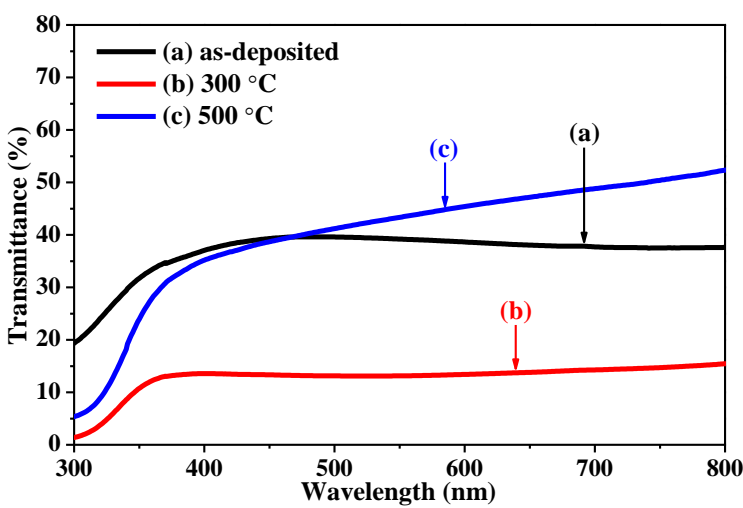

(a)

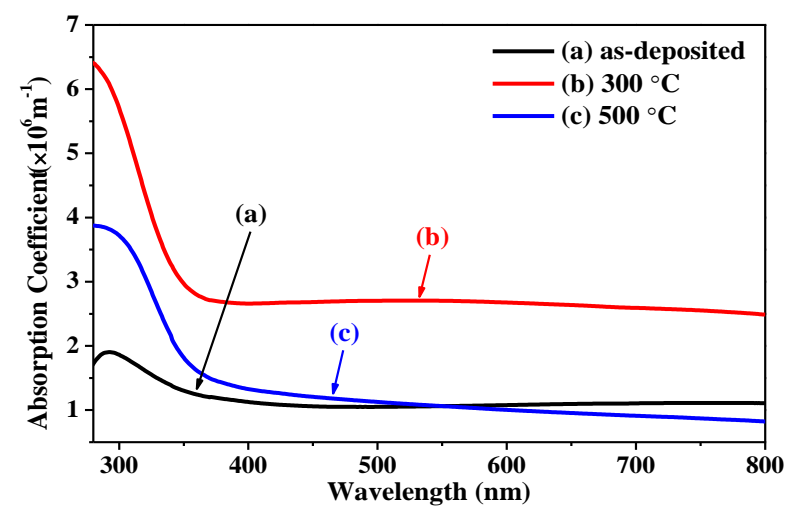

(b)

Figure 3. The (a) transmittance spectra, and (b) absorption coefficient of the nanosheet films

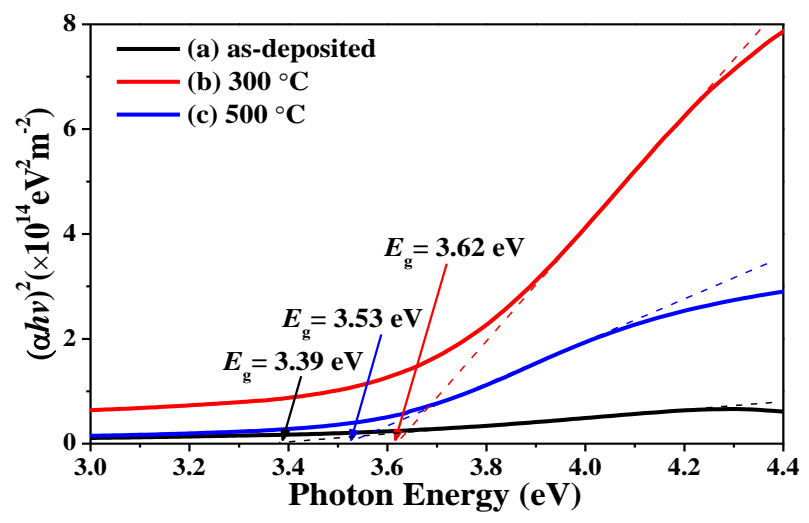

Figure 4. The Tauc's plot for optical bandgap estimation of NiO nanosheet films

\subsection{Humidity Sensing Performance}

Figure 5(a) represents the changes in the current signal of $\mathrm{NiO}$ nanosheet films-based humidity sensors at different annealing temperatures. The conducted ranges of the humidity sensing measurement are between $40 \% \mathrm{RH}$ to $90 \% \mathrm{RH}$. During the measurement, the ambient temperature was set to $25{ }^{\circ} \mathrm{C}$, and a voltage source of $5 \mathrm{~V}$ was applied across the electrodes. Based on the results, it can be observed that all nanosheet films produce good current responses with exponent curve to the increased humidity. The measurement results show a stable current value at $40 \% \mathrm{RH}$. When the humidity is increased to $90 \% \mathrm{RH}$, the current increases rapidly. Meanwhile, the current value decreases as the humidity level are reduced to $40 \%$ RH again. From the humidity sensing plot, the sensitivity, $S$ was calculated by (2):

$$
S=\frac{I_{\max }}{I_{\min }}
$$


where $I_{\max }$ and $I_{\min }$ are the current values at $90 \% \mathrm{RH}$ and $40 \% \mathrm{RH}$, respectively. The value of the sensitivity at different annealing temperatures is presented in Table 1. The results revealed that the NiO nanosheet film which annealed at $500{ }^{\circ} \mathrm{C}$ show the highest sensitivity of 257 . However, the as-deposited nanosheet film shows the lowest sensitivity at 154, while the annealed film at $300{ }^{\circ} \mathrm{C}$ shows the sensitivity of 195. The highest sensitivity produced by $500{ }^{\circ} \mathrm{C}$-annealed $\mathrm{NiO}$ may be caused by a hollow structure with highly porous as well as void density on the nanosheet surface. The porous surface of NiO plays an important role in enhanced the humidity response. Besides, specific surface area in $500{ }^{\circ} \mathrm{C}$-annealed nanosheet film would be more sensitive than others. In addition, the high sensitivity of $500{ }^{\circ} \mathrm{C}$-annealed sample can be attributed to the random distribution in the nanosheet size, high heterogeneity and specific surface area available for adsorption of water vapour. Generally, the humidity sensing mechanism based on $\mathrm{NiO}$ material can be followed through the description by Mamat et al. [20]. They mentioned that the quantity of water molecules available is very small at a low humidity level of $40 \% \mathrm{RH}$. At first, the water molecules are adsorbed on the nanosheet surface to form the chemisorbed layer. These water molecules formed the chemisorbed monolayer on the nanosheet surface by electrostatically attaches between $\mathrm{Ni}^{2+}$ and $\mathrm{OH}^{-}$as described in (3).

$$
\mathrm{Ni}^{2+}+\mathrm{H}_{2} \mathrm{O} \rightarrow \mathrm{Ni}-\mathrm{OH}+\mathrm{H}^{+}
$$

The reaction leaves $\mathrm{H}^{+}$ions, which jump from one site to another to contribute to the flow of electricity. At this stage, the value of the current of the sensor increases due to protonic conduction. When the humidity level increases, more water molecules are adsorbed on the nanosheet surface. The adsorbed water molecules can form hydrogen bonds between them that is between the chemisorbed $\mathrm{OH}$ - layer and oxygen atom $\mathrm{O}$ of water molecules. Therefore, the physisorbed water layer is formed on top of chemisorbed water monolayer. The thickness of the physisorbed water layer changes depending on the humidity level of RH. In general, if the $\mathrm{RH}$ level is increased, the thickness of the physisorbed water layer increase. Thus, more $\mathrm{H}^{+}$ ions are produced during the protonic conduction at high RH levels to contribute high current signals.

To confirm the stability and test the repeatability behaviour of the humidity sensor, the response of $500{ }^{\circ} \mathrm{C}$-annealed was measured for five cycles as shown in Figure 5(b). The identical curves of five cycles were observed nearly the same indicating that the sample of $500{ }^{\circ} \mathrm{C}$-annealed was very stable [25].

The response, $T_{r}$ and recovery, $T_{c}$ time were calculated from the humidity sensing response plots. These $T_{r}$ and $T_{c}$ values also are recorded in Table 1. As stated, the as-deposited film exhibits the fastest response time with $367 \mathrm{~s}$, while the $500{ }^{\circ} \mathrm{C}$-annealed film shows the fastest recovery time with $167 \mathrm{~s}$ towards humidity. This response and recovery time results may be caused by its specific surface area in as-deposited, $300{ }^{\circ} \mathrm{C}$, and $500{ }^{\circ} \mathrm{C}$-annealed films lead to a specific period of adsorption (response) and desorption (recovery) which is within $40 \% \mathrm{RH}$ to $90 \% \mathrm{RH}$.'

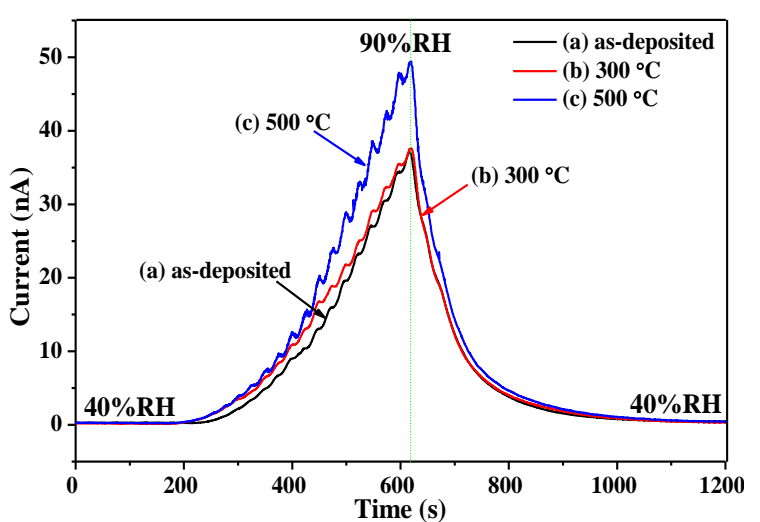

(a)

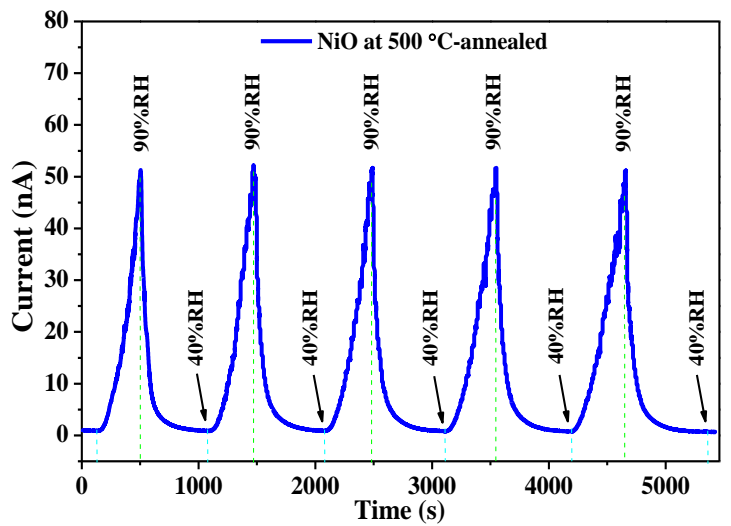

(b)

Figure 5. (a) Humidity responses at different annealing temperatures, and (b) repeatability behaviour of NiObased humidity sensor at annealing temperature of $500{ }^{\circ} \mathrm{C}$

Table 1. Humidity Sensing Properties of NiO at Different Annealing Temperatures

\begin{tabular}{lccc}
\hline \multicolumn{1}{c}{ Samples } & $T_{r}(\mathrm{~s})$ & $T_{c}(\mathrm{~s})$ & $S$ \\
\hline as-deposited & 367 & 174 & 154 \\
$300^{\circ} \mathrm{C}$ & 401 & 180 & 195 \\
$500{ }^{\circ} \mathrm{C}$ & 403 & 167 & 257 \\
\hline
\end{tabular}




\section{CONCLUSION}

In summary, the 2D NiO nanosheet films were successfully synthesized using a facile sonicated solgel immersion method at three different annealing temperatures. There were significant changes in films upon annealing. The XRD patterns show that $\mathrm{NiO}$ nanosheet films at annealing temperature of $300{ }^{\circ} \mathrm{C}$ and $500{ }^{\circ} \mathrm{C}$ have a pure polycrystalline structure, while the as-deposited revealed that the diffraction peak as $\mathrm{Ni}(\mathrm{OH})_{2}$. The FESEM images observation confirms that all nanosheet films exhibited a highly porous nanostructure. The $\mathrm{NiO}$ nanosheet film annealed at $500{ }^{\circ} \mathrm{C}$ has the highest transmittance percentage. Consequently, its absorption coefficient experienced a reduction. The different annealing temperatures also caused the bandgap energy changes. The effects of annealing temperature to humidity sensing properties were investigated, and their sensitivities were calculated. From this study, the best sensitivity humidity sensor produced by the sample annealed at $500{ }^{\circ} \mathrm{C}$ with a value of 257 , while the as-deposited sample shows the fastest response and recovery time.

\section{ACKNOWLEDGEMENTS}

This work is financially supported by the REI grant (600-IRMI/REI 5/3 (017/2018)). The work is also supported by the ASEAN-India Research \& Training Fellowship (IMRC/AISTDF/R\&D/P-1/2017). The authors would like to thank Ministry of Education Malaysia (Higher Education) and Faculty of Electrical Engineering, UiTM Shah Alam for their contribution of this research.

\section{REFERENCES}

[1] A. Kumar, M. Kumar, R. Kumar, R. Singh, B. Prasad, and D. Kumar, "Numerical model for the chemical adsorption of oxygen and reducing gas molecules in presence of humidity on the surface of semiconductor metal oxide for gas sensors applications," Materials Science in Semiconductor Processing, vol. 90, pp. 236-244, 2019.

[2] A. P. Dral and J. E. ten Elshof, "2D metal oxide nanoflakes for sensing applications: Review and perspective," Sensors and Actuators B: Chemical, vol. 272, pp. 369-392, 2018.

[3] N. Parimon, M. H. Mamat, M. A. R. Abdullah, A. S. Ismail, W. R. W. Ahmad, I. B. S. Banu, and M. Rusop, "Nanocarnation-like Nickel Oxide Thin Film: Structural and Optical Properties," International Journal of Engineering \& Technology, vol. 7, no. 4.18, pp. 103-106, 2018.

[4] K. Wetchakun, T. Samerjai, N. Tamaekong, C. Liewhiran, C. Siriwong, V. Kruefu, A. Wisitsoraat, A. Tuantranont, and S. Phanichphant, "Semiconducting Metal Oxides as Sensors for Environmentally Hazardous Gases," Sensors and Actuators B: Chemical, vol. 160, no. 1, pp. 580-591, 2011.

[5] C. Wang, L. Yin, L. Zhang, D. Xiang, and R. Gao, " Metal oxide gas sensors: sensitivity and influencing factors," Sensors, vol. 10, no. 3, pp. 2088-2106, 2010.

[6] M. J. Lawrence, A. Kolodziej, and P. Rodriguez, "Controllable Synthesis of Nanostructured Metal Oxide and Oxyhydroxide Materials via Electrochemical Methods," Current Opinion in Electrochemistry, vol. 10, pp. 7-15, 2018.

[7] S. A. Makhlouf and K. M. S. Khalil, "Humidity Sensing Properties of $\mathrm{NiO} / \mathrm{Al}_{2} \mathrm{O}_{3}$ Nanocomposite Materials," Solid State Ionics, vol. 164, no. 1-2, pp. 97-106, 2003.

[8] V. Jeseentharani, B. Jeyaraj, J. Pragasam, A. Dayalan, and K. S. Nagaraja, "Humidity Sensing Properties of CuO, $\mathrm{ZnO}$ and NiO Composites," Sensors \& Transducers Journal, vol. 113, no. 2, pp. 48-55, 2010.

[9] P. Pascariu, A. Airinei, N. Olaru, I. Petrila, V. Nica, L. Sacarescu, and F. Tudorache, "Microstructure, Electrical and Humidity Sensor Properties of Electrospun NiO- $\mathrm{SnO}_{2}$ Nanofibers," Sensors and Actuators B: Chemical, vol. 222, pp. 1024-1031, 2016.

[10] D. Li, Y. Li, F. Li, J. Zhang, X. Zhu, S. Wen, and S. Ruan, "Humidity Sensing Properties of $\mathrm{MoO}_{3}-\mathrm{NiO}$ Nanocomposite Materials," Ceramics International, vol. 41, no. 3, pp. 4348-4353, 2015.

[11] S. K. Kuanr, G. Vinothkumar, and K. S. Babu, "Substrate Temperature Dependent Structural Orientation of EBPVD Deposited NiO Films and its Influence on Optical, Electrical Property," Materials Science in Semiconductor Processing, vol. 75, pp. 26-30, 2018.

[12] M. R. Das, A. Mukherjee, and P. Mitra, " Structural, optical and ac electrical characterization of CBD synthesized NiO thin films: Influence of thickness," Physica E: Low-dimensional Systems and Nanostructures, vol. 93, pp. 243-251, 2017.

[13] L. John Kennedy, P. Magesan, J. Judith Vijaya, M. J. Umapathy, and U. Aruldoss, "Biominerals doped nanocrystalline nickel oxide as efficient humidity sensor: A green approach," Materials Science and Engineering B: Solid-State Materials for Advanced Technology, Article vol. 190, pp. 13-20, 2014.

[14] K. O. Ukoba, A. C. Eloka-Eboka, and F. L. Inambao, "Review of nanostructured NiO thin film deposition using the spray pyrolysis technique," Renewable and Sustainable Energy Reviews, vol. 82, pp. 2900-2915, 2018.

[15] M. M. Gomaa, G. R. Yazdi, S. Schmidt, M. Boshta, V. Khranovskyy, F. Eriksson, B. S. Farag, M. B. S. Osman, and R. Yakimova, "Effect of precursor solutions on the structural and optical properties of sprayed NiO thin films," Materials Science in Semiconductor Processing, vol. 64, pp. 32-38, 2017. 
[16] P. A. Sheena, K. P. Priyanka, N. A. Sabu, B. Sabu, and T. Varghese, "Effect of Calcination Temperature on the Structural and Optical Properties of Nickel Oxide Nanoparticles," Nanosystems: Physics, Chemistry, Mathematics, vol. 5, no. 3, pp. 441-449, 2014.

[17] Z. El khalidi, B. Hartiti, S. Fadili, and P. Thevenin, "Nickel Oxide Optimization using Taguchi Design for Hydrogen Detection," International Journal of Hydrogen Energy, vol. 43, no. 27, pp. 12574-12583, 2018.

[18] L. G. Teoh and K.-D. Li, "Synthesis and Characterization of NiO Nanoparticles by Sol-Gel Method," Materials Transactions, vol. 53, no. 12, pp. 2135-2140, 2012.

[19] L. S. Nair, D. Chandran, V. M. Anandakumar, and K. Rajendra Babu, "Structure and Room-temperature Ferromagnetism Evolution of Sn and Mn-doped NiO Synthesized by a Sol-gel Process," Ceramics International, vol. 43, no. 14, pp. 11090-11096, 2017.

[20] M. H. Mamat, N. Parimon, M. A. R. Abdullah, A. S. Ismail, M. F. Malek, W. R. W. Ahmad, A. S. Zoolfakar, A. B. Suriani, M. K. Ahmad, N. Nayan, I. B. S. Banu, R. Amiruddin, and M. Rusop, "Fabrication of Nickel Oxide Nanowall Network Films at Different Annealing Temperatures for Humidity Sensing Applications," International Journal of Engineering \& Technology, vol. 7, no. 4.18, pp. 277-282, 2018.

[21] J. Zhao, H. Liu, and Q. Zhang, "Preparation of NiO Nanoflakes under Different Calcination Temperatures and Their Supercapacitive and Optical Properties," Applied Surface Science, vol. 392, pp. 1097-1106, 2017.

[22] P. Malliga, J. Pandiarajan, N. Prithivikumaran, and K. Neyvasagam, "Influence of Film Thickness on Structural and Optical Properties of Sol-Gel Spin Coated $\mathrm{TiO}_{2}$ Thin Film," IOSR Journal of Applied Physics, vol. 6, no. 1, pp. 22-28, 2014.

[23] A. Yazdani, H. Zafarkish, and K. Rahimi, " The variation of E g -shape dependence of NiO nanoparticles by the variation of annealing temperature," Materials Science in Semiconductor Processing, vol. 74, pp. 225-231, 2018.

[24] W. R. W. Ahmad, M. H. Mamat, Z. Khusaimi, A. S. Ismail, and M. Rusop, "Impact of Annealing Temperature to the Performance of Hematite-based Humidity Sensor," Indonesian Journal of Electrical Engineering and Computer Science, vol. 13, pp. 1079-1086, 2019.

[25] A. S. Ismail, M. H. Mamat, M. F. Malek, M. M. Yusoff, R. Mohamed, N. D. M. Sin, A. B. Suriani, and M. Rusop, "Heterogeneous $\mathrm{SnO} / \mathrm{ZnO}$ nanoparticulate film: Facile synthesis and humidity sensing capability," Materials Science in Semiconductor Processing, vol. 81, pp. 127-138, 2018.

\section{BIOGRAPHIES OF AUTHORS}

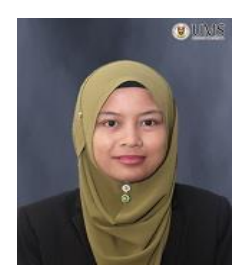

N. Parimon received her Bachelor and Master degrees in electrical \& electronic engineering, and electrical engineering, respectively from Universiti Teknologi Malaysia (UTM). She is a Lecturer at Universiti Malaysia Sabah and currently pursuing her Ph.D. at Universiti Teknologi MARA, Malaysia where she is working on the fabrication of metal oxide-based humidity sensors

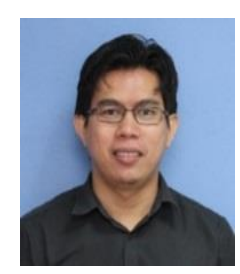

M. H. Mamat received his Bachelor degree in electrical \& electronic engineering and information engineering from Nagoya University, Japan and both of his Ph.D. and Master degrees in electrical engineering from Universiti Teknologi MARA, Malaysia. He is currently a Senior Lecturer at Universiti Teknologi MARA. His research interests range over metal oxide semiconductors and nanodevices

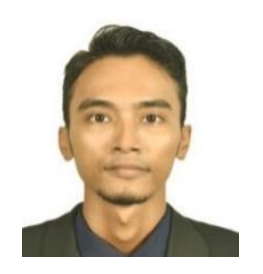

A. S. Ismail received his Bachelor and Master degree in electrical engineering from Universiti Teknologi MARA. He is currently pursuing his Ph.D. at Universiti Teknologi MARA, Malaysia where he is working on the fabrication of metal oxide nanosensors using the solution-based method.

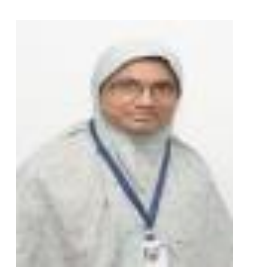

I. B. Shameem Banu received her first Ph.D. in physics from Madurai Kamaraj University. She received her second Ph.D. in condensed material physics from Anna University, Chennai. She is currently a professor at B.S. Abdur Rahman Crescent Institute of Science and Technology, India. 


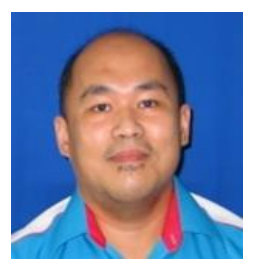

M. K. Ahmad received his Bachelor in electrical engineering from Gunma University, Japan. He received his Master degree in electrical engineering from Universiti Teknologi MARA, Malaysia. He received his Ph.D. from Shozuoka University, Japan. He is currently an Assoc. Professor at University Tun Hussein Onn, Malaysia.

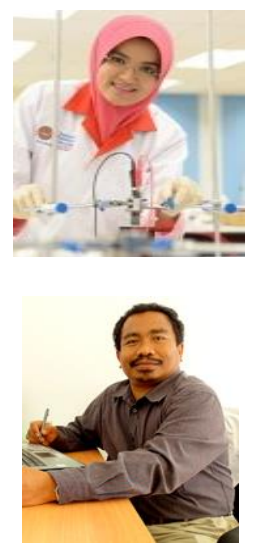

A. B. Suriani received her Bachelor and Master degree in physics from Universiti Teknologi Malaysia (UTM). She received her Ph.D. in physics at Universiti Teknologi MARA. She is currently a professor at Universiti Perguruan Sultan Idris, Malaysia.

M. Rusop received his Bachelor in engineering from Nagoya University, Japan. He received his Master and Ph.D. in engineering from Nagoya Institute of Technology, Japan. He is currently a professor in Universiti Teknologi MARA, Malaysia. 